\title{
Production of Modified C-Reactive Protein in U937-Derived Macrophages
}

\author{
By: Irina Ciubotaru ${ }^{*}$, Lawrence A. Potempa ${ }^{\dagger}$, AND Rosemary C. Wander ${ }^{\star}$
}

Ciubotaru, I., Potempa, L.A., and Wander, R.C. 2005. Production of modified C-reactive protein in U937-derived macrophages. Experimental Biology and Medicine. Nov 230(10):762-

70. http://www.ebmonline.org/cgi/content/abstract/230/10/762

\section{***Note: Figures may be missing from this format of the document}

\begin{abstract}
:
Plasma C- reactive protein (CRP) has been proposed to be a strong independent predictor for cardiovascular disease. This circulating form of CRP (native CRP or nCRP) is well described. Recently, the existence of a conformationally distinct isoform of CRP (modified CRP or mCRP) has been reported. The relevance of each CRP isoform to atherosclerotic disease is unknown. The purpose of this study was to examine the natural expression of CRP in undifferentiated, differentiated, and stimulated macrophages, cells known to contribute to atherogenesis in vivo, and to determine whether transcribed CRP was expressed as nCRP or mCRP. Macrophages were generated from U937 monocytes using phorbol 12-myristate 13-acetate. Differentiated macrophages were further stimulated with lipopolysaccharides (LPS). In undifferentiated, differentiated, and stimulated cells, CRP expression was assessed by reverse transcriptionpolymerase chain reaction, and CRP protein production was measured by fluorescence microscopy and flow cytometry (cellular CRP) or high-sensitivity enzyme-linked immunosorbent assay (secreted CRP). CRP transcript was minimally expressed in undifferentiated cells. Expression increased markedly in macrophages during differentiation and was not affected by LPS at $24 \mathrm{hrs}$. Cellular CRP protein increased in a time-dependent manner after LPS stimulation, and this induction was mediated via interleukin (IL)-6 and IL-1p. A small amount of secreted CRP was detected in the media of differentiated cells, but it was not significantly increased after LPS stimulation. Using specific monoclonal antibodies, our data indicate that cellular CRP is directly translated as the mCRP rather than the nCRP isomer. These results indicate that U937-derived macrophages are a good cell model to further study the production of mCRP under conditions relevant for the atherogenic process. Exp Biol Med 230:762-770, 2005
\end{abstract}

\section{Article:}

Seven decades after its discovery, the acute-phase protein C-reactive protein (CRP) has emerged as a strong predictor for cardiovascular disease. These observations have accumulated as highly sensitive assays for the measurement of previously undetectable concentrations of circulating CRP became commercially available. Hence, low concentrations of CRP are sometimes denoted as high-sensitivity CRP (hs-CRP) to indicate the use of such assays. Recent studies conducted in healthy men and women indicate that plasma CRP concentrations as low as $1-3 \mathrm{gg} / \mathrm{ml}$ may

\footnotetext{
* Department of Nutrition, The University of North Carolina at Greensboro, Greensboro, North Carolina 27403

${ }^{\dagger}$ Immtech International, Inc., 150 Fairway Drive, Suite 150,

Vernon Hills, Illinois 60061-1860

${ }^{\ddagger}$ Department of Nutrition, The University of North Carolina at Greensboro, Greensboro, North Carolina 27403

This work was funded by a Sigma Xi Grant-in-Aid that was awarded to C.I. and R.C.W. in October 2003.
} 
indicate an increased risk for future cardiovascular incidents (1-3). Therefore, hs-CRP was endorsed by the Centers for Disease Control and Prevention and by the American Heart Association for use in conjunction with a plasma lipid profile as part of global risk prediction for heart disease (4). Accumulating data indicate that CRP is not only a marker, but also an active player in the development of cardiovascular pathology (5). The latter aspect refers mainly to the association between CRP and processes of inflammation and the suggestion that it may modulate the low-grade inflammation that underlies atherogenesis. CRP has been reported to have both pro- and anti-inflammatory properties, so its exact role in the development of atherosclerosis remains an area of intense study.

As an acute phase protein, CRP plasma levels are known to increase from $-1 \mathrm{gg} / \mathrm{ml}$ to over 500 $\mathrm{gg} / \mathrm{ml}$ within 24-72 hrs of severe tissue-damaging events such as those caused by trauma, progressive cancer, acute myocardial infarction, and bacterial sepsis (6). Hence, the comparatively low levels of CRP qualified as predictive of heart disease require alternative thinking with regard to their possible biological relevance in early-stage disease. The widely held dogma is that CRP is produced exclusively by the liver (7), from which it is secreted into the circulation. Furthermore, any CRP found associated with distant tissue sites is perceived to originate from this circulating plasma pool. With the development of polymerase chain reaction (PCR) technology, however, it is now apparent that CRP transcript is expressed in various extrahepatic cells, including cells found in and around blood vessels (8-14). Few reports have characterized the translated product of the CRP transcript. In light of the evolving understanding that the different isoforms of CRP have distinct bioactivities, it is important to understand the nature of the synthesized CRP. To date, two CRP isomers have been described, namely native CRP (nCRP) and modified CRP (mCRP). Native CRP is composed of five non-covalently bound globular subunits arranged as a cyclic annular disc. This isoform is known to be synthesized by hepatocytes and represents the circulating form of the protein. Native CRP binds to substrates displaying phosphorylcholine moieties in a calcium-dependent manner, and when complexed, nCRP can activate the Complement system. Modified CRP is a conformationally distinct, poorly soluble isoform associated with a free CRP subunit. It can be irreversibly generated from nCRP by nonproteolytic dissociation of the pentameric disc. The "modified" subunits tend to self-aggregate (15-17). Antigens cross-reactive with its distinctive antigenicity have been found in various tissues or cells or as a membrane- bound protein (i.e., tissue-based CRP) $(8,12,18-21)$. In vitro, mCRP can be produced from nCRP by exposing nCRP to heat, urea, or acidic conditions, generally in the absence of calcium ions (17). Modified CRP can also spontaneously form from nCRP with storage. When the human CRP subunit gene was first isolated and expressed in Xenopus oocytes, the pre-CRP translation product containing an 18-amino acid leader sequence and expressed mCRP antigenic epitopes in preference to nCRP epitopes (22).

In vitro studies have reported that CRP is a proatherogenic protein with chemoattractant properties toward monocytes (23). In addition, CRP stimulated the expression of adhesion molecules (24), facilitated the uptake of low density lipoprotein in the intima, thereby promoting foam- cell formation (25); activated the complement system (26); and impeded vasorelaxation (27). None of these studies differentiated the possible effects of nCRP from those of mCRP. In vitro studies directly addressing the distinct isoforms of CRP have reported that mCRP displays proinflammatory effects on neutrophils, endothelial cells, and platelets, while nCRP displays 
anti-inflammatory activities (28-31). These studies used exogenously added CRP and did not address the existence and possible role of naturally occurring protein. The effects of cellexpressed CRP may be significant in unraveling the role of CRP in coronary vessel disease.

The present study was initiated to determine whether CRP was expressed by cells such as macrophages that are present in the atherosclerotic milieu and whether pro- inflammatory stimuli such as lipopolysaccharides (LPS) could affect CRP expression. This study also directly addressed, for the first time, the isoforms of CRP produced by the U937-derived macrophages.

\section{MATERIALS AND METHODS}

Cell Culture.

U937 human promonocytic cells (CRL1593.2; American Type Culture Collection, Manassas, VA) were grown in RPMI 1640 medium (Sigma Chemical Co., St. Louis, MO) supplemented with $10 \%$ fetal bovine serum (FBS), $1 \%$ L-glutamine, $1 \%$ penicillin/streptomycin, and $0.2 \%$ amphotericin B. Cells within three passages were differentiated into macrophages by stimulation with $10 \mathrm{nM}$ phorbol 12-myristate 13-acetate (PMA) for $72 \mathrm{hrs}$. Differentiation was determined by increased cell attachment to the flasks and by changes in cell morphology, namely larger cell size, increased membrane ruffles, and small nucleus and large cytoplasm filled with vacuoles. In some experiments, the CRP production was assessed in response to LPS stimulation $(1 \mu \mathrm{g} / \mathrm{ml}$ LPS for 24-72 hrs). Optimization studies were also conducted to ensure that the production of CRP in PMA-differentiated macrophages was not modified when cells were maintained in media without LPS for 24-72 hrs post-differentiation (data not shown).

\section{Antibodies and Chemicals.}

Several monoclonal mouse anti-human CRP antibodies (mAbs) were used as primary antibodies in indirect immunofluorescence procedures (Table 1). Clone-8 CRP mAb was purchased from Sigma Chemical. According to the manufacturer, this antibody recognizes both native and denatured CRP isoforms. The 8D8, 8C10, and 9C9 mAbs were provided by Dr. L. Potempa and prepared as previously described (32). The 8D8 mAb specifically reacts with nCRP, and the 8C10 and 9C9 mAbs react with mCRP. The 9C9 mAb recognizes the C-terminal octapeptide of the CRP subunit, which is buried within the intersubunit contact regions of the nCRP structure and is expressed when the subunits are dissociated. The $8 \mathrm{C} 10 \mathrm{mAb}$ recognizes an epitope on the $\mathrm{N}$ - terminal $16-\mathrm{kDa}$ fragment of the mCRP isoforms (33). This epitope is conformationally sensitive, requiring the single intrachain disulfide bond of the CRP subunit, in the mCRP isoform, to be intact.

The secondary antibody used in indirect immunofluorescence procedures was a FITC-F(ab') goat anti-mouse IgG (Jackson Immunoresearch Laboratories, Inc., West Grove, PA). In fluorescence microscopy studies, this tag gave a green signal for positive staining when captured with the fluorescein filter. For flow cytometry studies, the wavelength emission of this fluorochrome required the FL1 channel for data acquisition (excitation wavelength: $488 \mathrm{~nm}$; emission wavelength: $525 \mathrm{~nm}$ ).

For neutralization studies, monoclonal mouse antihuman interleukin (IL)-10 and IL-6 antibodies (R\&D Systems, Minneapolis, MN) were used. These mAbs are known to efficiently neutralize circulating IL-1 $\beta$ and IL-6 (34). All the chemicals were purchased from Sigma Chemical, unless stated otherwise. 


\section{RNA Isolation.}

RNA isolation was performed using the RNeasy mini-kit (Qiagen, Inc., Valencia, CA), according to manufacturer's instructions.

\section{Table 1. Primary Antibodies Used to Identify C-Reactive Protein (CRP) Isoforms in U937- Derived Macrophages}

\begin{tabular}{|c|c|c|}
\hline Antibody & Source & CRP isoform \\
\hline $9 \mathrm{C9}$ & $a$ & $\begin{array}{l}\text { Modified CRP } \\
\text { (C-terminal octapeptide) }\end{array}$ \\
\hline $8 C 10$ & $a$ & $\begin{array}{l}\text { Modified CRP } \\
\text { (N-terminal } 16 \mathrm{kd} \text { fragment) }\end{array}$ \\
\hline 8D8 & a & Native CRP \\
\hline Clone 8-CRP & Sigma & Native/denatured CRP \\
\hline
\end{tabular}

${ }^{a}$ Contributed by Dr. L. Potempa.

${ }^{b}$ Modified and denatured CRP are synonymous and refer to CRP that has lost its pentameric structure.

Reverse Transcription (RT)-PCR.

RT-PCR was performed using the One-Step RT-PCR kit (Qiagen) and the following CRP primers (Invitrogen Life Technologies, Carlsbad, CA): sense: TCGTATGCCACCAAGAGACA AGACA; antisense: AACACTTCGCCTTGCACTTCATACT (11); 18S ribosomal RNA (Ambion, Austin, TX) provided an internal standard. The 100-base pair (bp) ladderwas purchased from New England BioLabs (Beverly, MA).Reactions were carried out using $1 \mathrm{gg}$ RNA. PCR amplification was conducted for 30 secs at $94^{\circ} \mathrm{C}, 30$ secs at $55^{\circ} \mathrm{C}$, and 1 min at $72^{\circ} \mathrm{C}$. The reaction was optimized for 35 cycles. Amplified DNA was separated on a 1.5\% agarose gel containing $1 \mathrm{pl}$ ethidium bromide $(10 \mathrm{mg} / \mathrm{ml})$ and wasquantified using a Kodak imaging station 440 CF (Rochester, NY). The amplification of genomic DNA was excluded by running samples for which the RT step hadbeen omitted.

\section{Immunofluorescence Studies.}

The presence of the protein in macrophages was determined using fluorescence microscopy and flow cytometry in both live andfixed cells. Live cells were used to identify membraneexpressed CRP, while fixed cells were screened for total cellular CRP. In addition, live cells were permeabilized withsaponin for a closer analysis of CRP intracellular distribution after the extraction of soluble cytoplasmic components.Primary antibodies were used in a dilution of 1 to 500 (purified clone CRP-8 mAb) or 1 to 20 (murine hybridomaculture supernatants of 8D8, 8C10, and 9C9 mAbs), and thesecondary FITC-conjugated antibody was used in a dilution of 1 to 400 . For immunostaining of live cells, cells were grown on poly-L-lysine-coated slides and were then successively incubated with primary and secondary antibodies diluted in blocking buffer (3\% bovine serumalbumin/phosphate-buffered saline [BSA/PBS]). Cells wereincubated with the primary antibody overnight, washed withblocking solution twice, and then exposed to the secondary antibody for $1.5 \mathrm{hrs}$ in the dark. All the steps were performed at $4{ }^{\circ} \mathrm{C}$. Immunostaining of 
fixed cells was performed in macrophages that had been attached onto poly-L-lysine-coated slides after PMA-induced differentiation and, in some experiments, in undifferentiated U937 monocytes that had been attached to the slides by cytospinning. Briefly, 1 x $10^{5}$ cells were loaded onto slides in Cytospin Chambers (StatSpin, Norwood, MA) and werecytospun in a Cytofuge (StatSpin) for 4 mins at $850 \mathrm{rpm}(40 \mathrm{~g})$. Once cells were adherent to the slides, they were fixed with $3.7 \%$ formaldehyde, washed with $2 \%$ glycine/3\% BSA/PBS to quench excess reactive aldehydes, and thenpermeabilized with $0.1 \%$ saponin. Cells were blocked with $3 \%$ $\mathrm{BSA} / \mathrm{PBS}-0.1 \%$ saponin for $30 \mathrm{mins}$ at $4{ }^{\circ} \mathrm{C}$. All the antibodies were diluted in the blocking solution. Cells wereincubated with the primary antibody overnight at $4{ }^{\circ} \mathrm{C}$, washed with blocking solution twice, and then exposed to the secondary antibody for $1.5 \mathrm{hrs}$ at room temperature in the dark. For both live and fixed cells, after the incubation with the secondary antibody, slides were thoroughly washed, mounted, and then analyzed using fluorescence microscopy. For live cells permeabilized with saponin, the same steps were taken as for the staining of live cells, but $0.1 \%$ saponin was included in all the buffers, as described in the staining of fixed cells. After adequate washing, images were captured with a SPOT digital camera mounted on an Olympus BX60 fluorescence microscope.

For flow cytometry, cells grown in six-well plates were detached using a rubber policeman and collected in polystyrene tubes in ice-cold PBS containing $0.1 \%$ sodium azide. The staining procedures for fixed and live cells were performed in a manner similar manner to that described above. Cells were analyzed using a Becton-Dickinson FACSCalibur flow cytometer (BD Biosciences, San Jose, CA). Negative (unstained cells) and isotype (cells incubated only with the secondary antibody) controls were included for each sample. The cell population used for acquiring data was gated to exclude any debris that would increase the nonspecific signal. Quantitative data were collected from 10,000 cells and were reported as mean fluorescence intensity (MFI).

Enzyme-Linked Immunosorbent Assay (ELI-SA).

Soluble CRP secreted by macrophages was measured in the supernatant using a high-sensitivity assay (hs-ELISA; Diagnostic Systems Laboratories, Inc., Webster, TX). Prior to the assay the supernatant was concentrated 5-fold using Vivaspin 6 concentrating devices (Vivascience, Hannover, Germany).

Statistical Analyses.

To ensure reproducibility, experiments were conducted in duplicate and were conducted at least three times. Statistical analyses (one-way analysis of variance [ANOVA], Student's t test) were performed on data gathered from three experiments. The level of significance was set at the 0.05 level.

\section{RESULTS}

\section{CRP Transcript.}

The expression of CRP was assessed by RT-PCR in U937 monocytes (undifferentiated monocytes), in U937 monocytes differentiated to macrophages using PMA (PMA-differentiated macrophages), and 


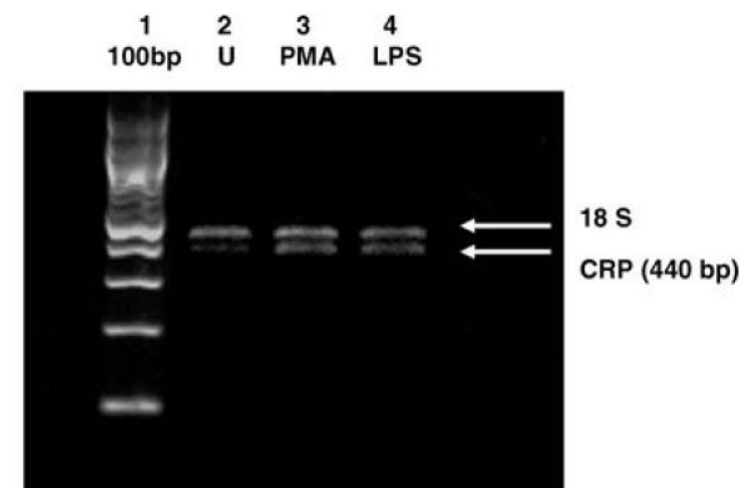

Figure 1. The expression of CRP in U937-derived macrophages. U937 cells $\left(5 \times 10^{6}\right)$ were seeded in $100-\mathrm{mm}$ cell culture dishes and differentiated into macrophages with $10 \mathrm{nM}$ PMA for $72 \mathrm{hrs}$ in the presence of RPMI medium containing $10 \%$ FBS. When the differentiation was terminated, cells were washed with PBS and then incubated in fresh media alone or in media containing $1 \mu \mathrm{g} / \mathrm{ml}$ LPS for another $24 \mathrm{hrs}$. After $24 \mathrm{hrs}$, cells were collected by scraping, and RT-PCR was performed on RNA isolated from U937 undifferentiated monocytes (Lane 2, U), PMAdifferentiated macrophages (Lane 3, PMA), and LPS-stimulated macrophages (Lane 4, LPS). Lane 1 represents the 100-bp DNA ladder marker. 18S rRNA was used as an internal control. The results presented are representative of triplicate experiments.

in macrophages stimulated with $1 \mu \mathrm{g} / \mathrm{ml}$ LPS for $24 \mathrm{hrs}$ (LPS-stimulated macrophages). CRP transcript (440 bp) was detected in similar amounts in macrophages before and after LPS stimulation, but was only minimally detected in undifferentiated U937 cells (Fig. 1). In two other experiments, no CRP expression was detected in undifferentiated U937 monocytes (data not shown). Collectively, these three experiments indicate increased gene expression of CRP in differentiated and stimulated U937-derived macrophages compared to undifferentiated U937 monocytes, and they indicate that undifferentiated cells may express low levels of CRP transcript.

\section{CRP Protein.}

The presence of CRP protein was assessed in U937 undifferentiated monocytes (Fig. 2A) and in macrophages before (Fig. 2B) and after 24-hr stimulation with LPS (Fig. 2C). Fluorescence microscopy experiments were conducted in fixed cells using clone-8 CRP mAb. CRP protein was detected in very low amounts in U937 undifferentiated monocytes. Its production was significantly higher in differentiated macrophages and was not influenced by LPS stimulation. However, notable differences in cell morphology and in the amount and distribution of CRP were observed in response to LPS. For example, PMAdifferentiated macrophages prior to LPS stimulation were more round, with poorly developed filopodia, and they displayed homogeneous CRP staining, mainly in the perinuclear area. Conversely, LPS stimulation enhanced the cell spreading, polarization, and filopodia formation, changes that were accompanied by an increase in CRP, which showed a diffuse localization in the cytoplasm, sometimes with a tendency toward polarization.

Subsequent experiments were conducted to quantify the production of CRP before and after an LPS challenge in a time-course study. Macrophages were stimulated with LPS for 24-72 hrs. Flow cytometry analysis was performed on fixed cells using the clone-8 CRP mAb. LPSstimulated macrophages showed a significant increase in CRP compared to unstimulated macrophages (Fig. 3). The amount of CRP produced in response to LPS stimulation at any time point was greater than that measured in unstimulated macrophages $(\mathrm{P}<0.001)$. LPS-stimulated macrophages showed a time-dependent production of CRP, whereby the protein increased $60 \%$ 
from baseline in the first $24 \mathrm{hrs}$ and then increased an additional $25 \%$ between 24 and $48 \mathrm{hrs}(\mathrm{P}<$ 0.001). Between 48 and $72 \mathrm{hrs}$, there was no significant further increase in the production of CRP.

To test the involvement of proinflammatory cytokines IL-10 and IL-6, which have been identified as regulators of hepatic production of CRP, a neutralization study was conducted using flow cytometry in fixed cells. CRP was detected using clone-8 CRP mAb. Anti-IL-10 and IL-6 mAbs, which are known to neutralize these cytokines, were used at $50 \mu \mathrm{g} / \mathrm{ml}$ and were added to the media separately or in combination and simultaneously with LPS. The amount of CRP protein quantified after exposing macrophages to LPS for $72 \mathrm{hrs}$ in the absence of neutralizing mAbs was assigned a relative value of $100 \%$. In the presence of anti- IL-10 mAb, the relative level of CRP produced was decreased by 50\%. In the presence of anti-IL-6 mAb, production of CRP was decreased by $78 \%$. No synergistic or other effect on CRP synthesis was noted if both cytokines were neutralized at the same time by a combination of the two antibodies (Fig. 4).

Secreted CRP was measured by hs-ELISA in the culture supernatant above plate-immobilized macrophages. Culture supernatants were concentrated 5-fold prior to detection. The baseline concentration of CRP measured in PMA-differentiated macrophages was $10 \mathrm{ng} / \mathrm{ml}$. After stimulation with LPS for $72 \mathrm{hrs,} \mathrm{CRP} \mathrm{concentration} \mathrm{increased} \mathrm{slightly,} \mathrm{but} \mathrm{insignificantly,} \mathrm{to} 13$ $\mathrm{ng} / \mathrm{ml}$ (data not shown).

\section{CRP Isoforms.}

Fluorescence microscopy experiments conducted in both live and fixed cells showed that LPSstimulated macrophages produced mCRP, but not nCRP (Fig. 5). In live cells, mCRP was specifically identified using the $9 \mathrm{C} 9 \mathrm{mAb}$ that recognizes the $\mathrm{C}$-terminal octapeptide of the CRP subunit (Fig. 5A1). In these live cells, the $8 \mathrm{C} 10 \mathrm{mAb}$, which recognizes an epitope expressed on the N-terminal 16-kDa fragment and is dependent on an intact intrachain disulfide bond of mCRP, showed no staining (Fig. 5A2). The 8D8 mAb, which is specifically reactive with nCRP, also showed no staining (Fig. 5A3). An intense fluorescence was found when using the clone- 8 CRP mAb (Fig. 5A4).

In fixed cells (Fig. 5B), mCRP antigenicity identified by 9C9 mAb was strongly expressed (Fig. 5B1), while nCRP antigenicity identified by 8D8 mAb was negative (Fig. 5B3). In fixed cells, anti-mCRP 8C10 $\mathrm{mAb}$ reacted 
A
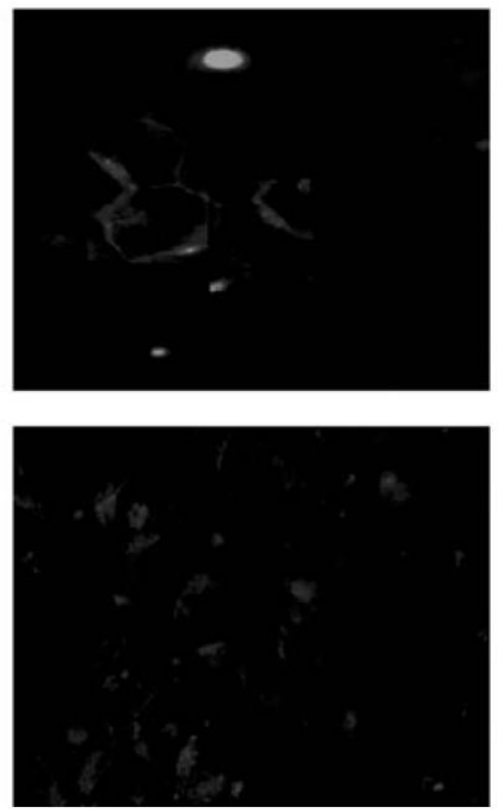

B
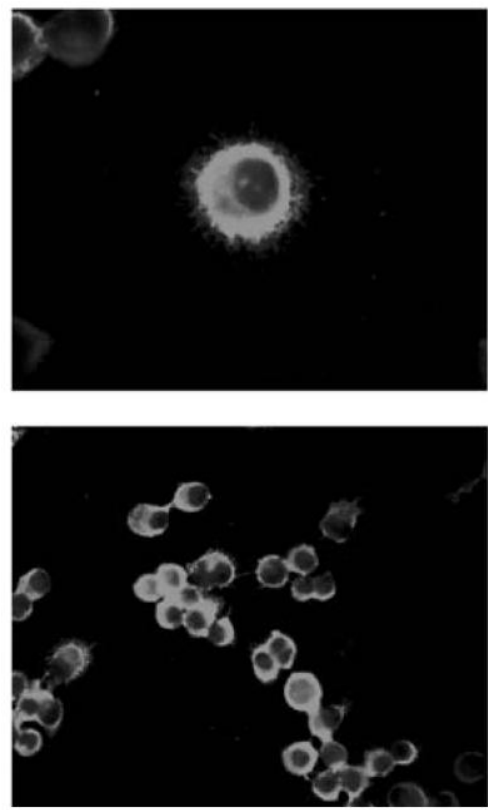

C
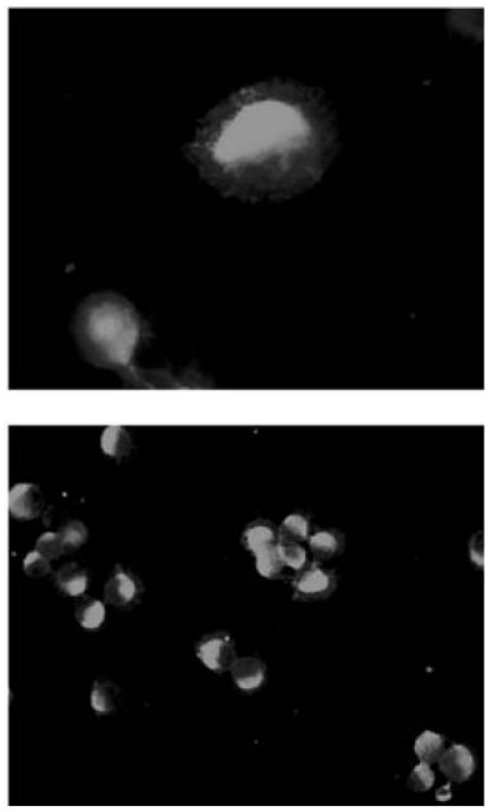

Figure 2. The production of CRP in U937-derived macrophages. U937 cells were attached to poly-L-lysine glass slides by cytospinning and used for immunostaining of undifferentiated monocytes. Also, U937 cells were attached to poly-L-lysine glass slides after differentiation into macrophages using $10 \mathrm{nM}$ PMA for $72 \mathrm{hrs}$ in the presence of RPMI medium containing 10\% FBS. Finally, differentiated cells were washed with PBS and then incubated in fresh media alone or in media containing $1 \mathrm{gg} / \mathrm{ml}$ LPS for another $24 \mathrm{hrs}$. After $24 \mathrm{hrs}$, these stimulated cells were prepared for immunostaining. CRP was identified in undifferentiated monocytes (Panel A) and in PMA-differentiated macrophages before (Panel B) and after (Panel C) LPS stimulation. Cells were fixed and immunostained as described in Methods. Clone-8 CRP mAb was used as primary antibody. Cells were analyzed using a fluorescence microscope with $\mathrm{x} 100$ and $\mathrm{x} 40$ magnifications. The results presented are representative of triplicate experiments.

with the same general distribution pattern and intensity as anti-mCRP 9C9 mAb (Fig. 5B2). As with live cells, intense fluorescence was found using clone-8 CRP mAb, showing a staining pattern analogous to that observed with both antimCRP mAbs (Fig. 5B4).

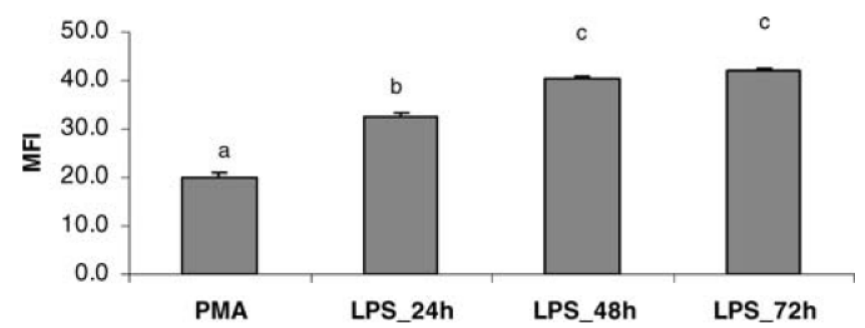

Figure 3. The effect of LPS on CRP production in U937-derived macrophages. U937 monocytes were seeded in sixwell plates and differentiated into macrophages with $10 \mathrm{nM}$ PMA for $72 \mathrm{hrs}$ in the presence of RPMI medium containing 10\% FBS. When the differentiation was terminated, cells were washed with PBS and then incubated in fresh media alone or in media containing $1 \mathrm{lg} / \mathrm{ml}$ LPS for another 24-72 hrs. Indirect staining was performed using clone-8 CRP as primary antibody and FITC-F(ab')2 goat anti-mouse IgG as secondary antibody. Cells were collected and analyzed by flow cytometry, and data were reported as mean fluorescence intensity (MFI). Values represent mean \pm SEM. Results from at least three experiments were analyzed using one-way ANOVA. Letters above bars designate significant differences among various time points $(\mathbf{P}<0.001)$. 
To further understand the differential reactivity of $8 \mathrm{C} 10 \mathrm{mAb}$ in live and fixed cells, we studied the presence of CRP isoforms in cells permeabilized with saponin but not fixed, since fixation procedures might interfere with epitope recognition by specific antibodies. The recognition pattern of mAbs toward CRP was similar to that found in live cells, in that mCRP was detected by 9C9 (Fig. 5C1) and clone-8 CRP mAbs (Fig. 5C4) but not by $8 \mathrm{C} 10 \mathrm{mAb}$ (Fig. 5C2). Native $\mathrm{CRP}$ was absent, as shown by the lack of staining obtained using the $8138 \mathrm{mAb}$ (Fig. 5C3).

Flow cytometry studies supported these findings (data not shown). In live cells, mCRP staining was detected using either 9C9 or clone-8 CRP mAbs, but not $8 \mathrm{C} 10 \mathrm{mAb}$. No nCRP was found with the anti-nCRP $8138 \mathrm{mAb}$. In fixed cells, CRP staining was detected using anti-mCRP 9C9 and $8 \mathrm{C} 10 \mathrm{mAbs}$ as well as with clone- $8 \mathrm{CRP} \mathrm{mAb}$, but not with anti-nCRP $8138 \mathrm{mAb}$.

\section{DISCUSSION}

Although the presence of CRP in atherosclerotic tissue has been clearly established, it is unknown whether CRP is deposited at these sites from the blood or is produced locally by cells involved in the development or control of the atherosclerotic lesion. What is also unknown, and which is relevant to truly understanding the bioactivities of CRP, is whether CRP protein that is found at atherosclerotic sites is present as the native-pentameric isoform, or as the distinct

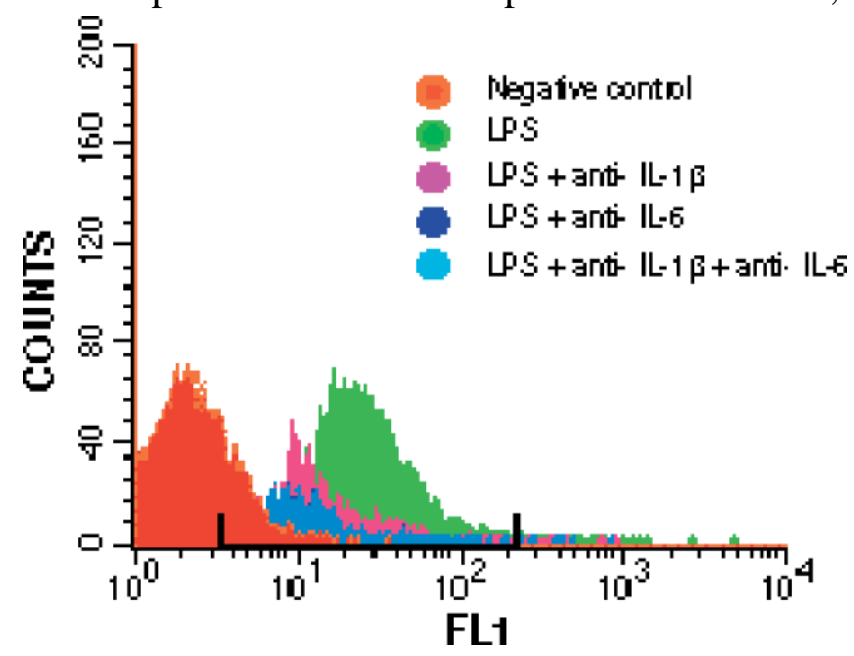

Figure 4. Cytokine-mediated CRP production in LPS-stimulated macrophages. U937 monocytes were seeded in sixwell plates and differentiated into macrophages with $10 \mathrm{nM}$ PMA for $72 \mathrm{hrs}$ in the presence of RPMI medium containing 10\% FBS. When the differentiation was terminated, cells were washed with PBS and then stimulated with $1 \mathrm{gg} / \mathrm{ml}$ LPS for $72 \mathrm{hrs}$. Anti-IL-1R and IL- $6 \mathrm{mAbs}(50 \mathrm{gg} / \mathrm{ml})$ were added to the media separately or in combination and simultaneously with LPS. Indirect staining was performed using clone-8 CRP as primary antibody and FITC$\mathrm{F}\left(\mathrm{ab}^{\prime}\right) 2$ goat anti-mouse IgG as secondary antibody. Cells were collected and analyzed by flow cytometry. The histogram presented is representative of two different experiments.

mCRP isoform. Yasojima et al. (11) have reported that CRP transcript and protein are expressed in macrophages and smooth muscle-like cells in or near atherosclerotic plaques. Supporting evidence also comes from Kobayashi et al. (14), who reported production of CRP in human coronary smooth muscle cells. Although the presence of CRP in the arterial wall is well established, the precise identification of the CRP isoform being expressed is unknown. Since a tissue-based form of CRP antigenically cross-reactive with mCRP has been reported to be expressed in normal blood vessel intima (8), its relevance to the development of atherosclerotic plaques requires clarification. 
The present study addresses the aforementioned questions using a cell model relevant for the atherogenic process in vivo, namely monocyte-derived macrophages. The expression of CRP transcript was minimally detected in undifferentiated monocytes and was clearly upregulated in PMA-differentiated macrophages. Further stimulation of PMA-differentiated macrophages with LPS for $24 \mathrm{hrs}$ did not increase the amount of CRP transcript. The fact that the expression of CRP is strongly induced upon differentiation may reflect a role for CRP during the cytoskeletal rearrangement that occurs during monocyte transition to macrophages, as has been previously suggested $(35,36)$.

Figure 5. Identification of CRP isoforms in LPS-stimulated macrophages. U937 monocytes were seeded onto polyL-lysine glass slides and differentiated into macrophages with $10 \mathrm{nM}$ PMA for 72 hrs in the presence of RPMI medium containing $10 \%$ FBS. When the differentiation was terminated, cells were washed with PBS and then further stimulated with $1 \mathrm{gg} / \mathrm{ml}$ LPS for $72 \mathrm{hrs}$. CRP was identified in live (Panel A), fixed (Panel B), or live cells permeabilized with $0.1 \%$ saponin (Panel C). The primary antibodies used were anti-Mcrp 9C9 mAb (1), anti-mCRP 8C10 mAb (2), anti-nCRP 8D8 (3), and Sigma clone-8 CRP mAb (4). Cells were analyzed using a fluorescence microscopy with a $\mathrm{x} 40$ magnification. The results presented are representative of triplicate experiments. 

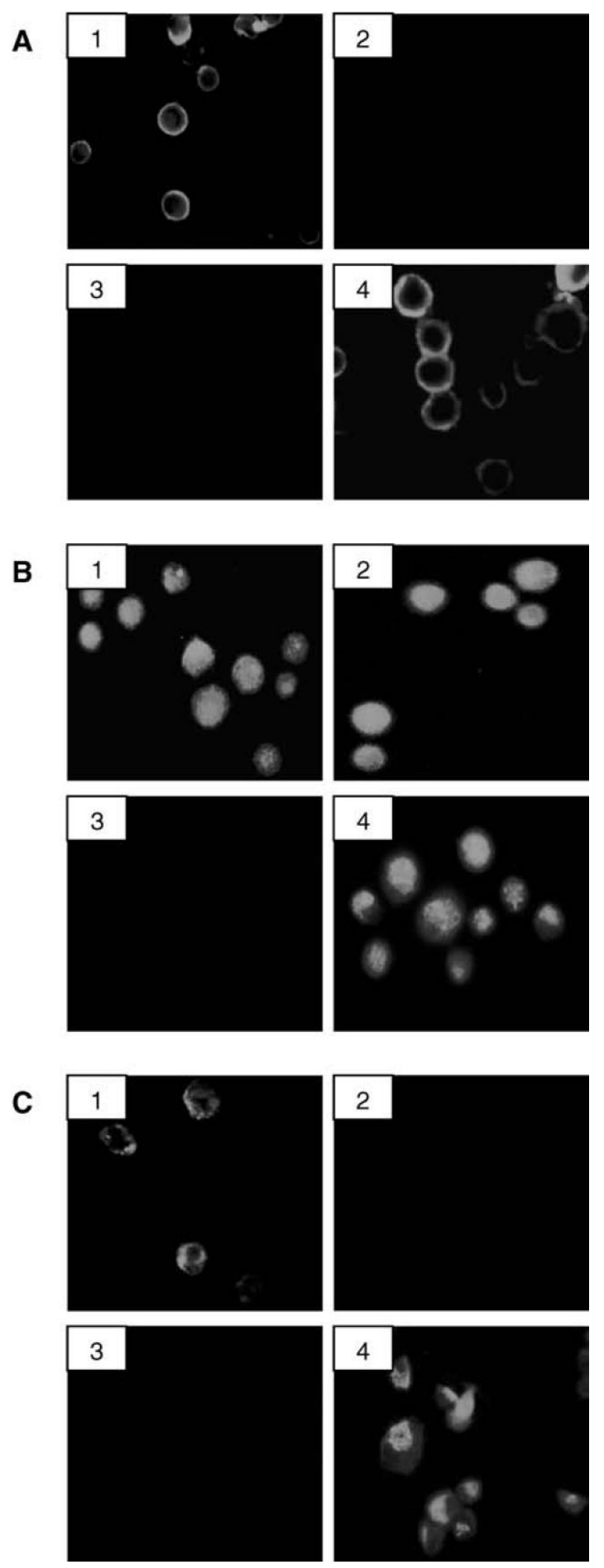
Further investigation of the effect of LPS on the production of CRP protein showed that LPS time-dependently increased the production of CRP, peaking at $48 \mathrm{hrs}$. After $24 \mathrm{hrs}$ of LPS stimulation, macrophages had a significantly higher amount of CRP protein compared with unstimulated, differentiated macrophages.

Besides the significant increase in the amount of CRP protein produced in response to a 24-hr LPS stimulation, there were also changes in macrophage morphology and in the amount and distribution of CRP protein, as detected by fluorescence microscopy. These aspects indicate a state of activity induced in macrophages by an LPS challenge.

Since there was no concurrent increase in the level of CRP mRNA level detected in PMAdifferentiated macrophages in the presence or absence of LPS stimulation, these results indicate that LPS modulates CRP synthesis at the translational rather than the transcriptional level. It has been previously suggested that differentiation is an inducer of gene transcription, but an additional stimulus is needed to promote translation (37). It is possible that in our study the presence of LPS was needed to efficiently promote the translation of CRP mRNA induced upon differentiation.

The LPS-induced production of nCRP has been studied mainly in hepatocytes and has been shown to be mediated by two proinflammatory cytokines, IL-10 and IL-6, which synergistically stimulate CRP $(38,39)$. Only recently has it been shown that CRP can be produced at extrahepatic sites in response to proinflammatory stimuli. Specifically, Jabs et al. (12) reported that in renal cortical epithelial cells, IL-6 is a better inducer of CRP transcript than is IL-10 and that conditioned media obtained from LPS-stimulated peripheral blood mononuclear cells led to a 1000-fold increase in the expression of this gene. Calabro et al. (40) found that the level of CRP transcript and concentration of CRP released from human coronary smooth muscle cells was greater in response to IL-6 than in response to IL-1 0 . The combination of the two cytokines and the LPS proved to be the strongest stimulants of CRP in these cells. Our results confirmed that using monocyte-derived macrophages, LPS-induced synthesis of CRP protein does involve these two cytokines, with IL-6 being the predominant cofactor. We were unable to demonstrate, however, an additive effect of these two cytokines on the CRP synthesis response.

In the present study, although LPS induced a time- dependent increase in the production of cellassociated CRP, the soluble CRP measured in macrophage supernatant was minimal and was not significantly affected by LPS stimulation. If extrapolated to in vivo conditions, this result indicates that it is unlikely that CRP released from macrophages contributes significantly to the overall plasma concentration of this protein.

Although there are other studies that reported the presence of small amounts of CRP in the supernatant of nonhepatic cells $(12,40,41)$, the identification of specific isoforms of CRP released from cells has not been addressed. To present, only Jabs et al. (12) reported the presence of denatured CRP in the supernatant of renal cortical tubular epithelial cells. In the present study, the ELISA kit used to measure soluble CRP did not allow a specification of CRP isoforms secreted in the media. 
The production of cell-expressed CRP protein was investigated using highly characterized monoclonal antibodies. In the present study we showed that LPS-stimulated macrophages produce mCRP rather than $\mathrm{nCRP}$, as the modified isoform was detected by the $9 \mathrm{C} 9 \mathrm{mAb}$ and the presence of native isoform was excluded by using the $8 \mathrm{D} 8 \mathrm{mAb}$. The results obtained using Sigma clone-8 CRP mAb were similar to those obtained using the 9C9 mAb raised specifically against the $\mathrm{mCRP}$ isoform. These observations are in agreement with findings previously reported by others, in that clone-8 CRP mAb recognizes mCRP and not nCRP $(12,13,42)$.

A conspicuous difference was found between live and fixed cells with regard to the way they stained in the presence of the 9C9 and 8C10 antibodies. In live cells, the 9C9 mAb raised against the $\mathrm{C}$-terminal of mCRP gave a positive staining in live cells, whereas the $8 \mathrm{C} 10 \mathrm{mAb}$ raised against the $\mathrm{N}$-terminal of mCRP was negative. In fixed cells, both $\mathrm{mAbs}$ gave a diffuse positive staining. These results indicate that the $\mathrm{C}$-terminal epitope is exposed on the outer side of the cell membrane, while the $\mathrm{N}$-terminal epitope is masked or embedded in the membrane. We hypothesized that this epitope became available to bind to its antibody as a consequence of fixation/permeabilization. To test this possibility, we performed fluorescence microscopy studies in live cells permeabilized with saponin, but not fixed. We found that the 9C9 but not the 8C10 $\mathrm{mAbs}$ detected mCRP, indicating that fixation is necessary to gain access to the $\mathrm{N}$ - terminal epitope recognized by the $8 \mathrm{C} 10 \mathrm{mAb}$. This result indicates that binding of $8 \mathrm{C} 10 \mathrm{mAb}$ to its epitope requires not only the access of the antibody to the inner part of the membrane but probably a conformational change that is induced by fixation (e.g., cross-linking). The 8C10 $\mathrm{mAb}$ is a less-robust antibody compared to 9C9 mAb, and its reactivity depends on the integrity of the intrachain disulfide bond of mCRP. Since the extent to which experimental procedures affected this structure is not known, the results obtained using the $8 \mathrm{C} 10 \mathrm{mAb}$ should be interpreted with caution. Further exploration of this aspect is needed.

Another aspect captured when comparing the immunostaining of live and live permeabilized cells was related to changes in the disposition of mCRP detected with the 9C9 and clone-8 CRP mAbs. The staining pattern obtained with the 9C9 mAb showed a more intense cytoplasmic mCRP, but still retained an annular disposition evoked by the staining of live cells in the absence of permeabilization. Conversely, clone-8 CRP mAb showed a total change in mCRP disposition, in that a strong signal was present in the cytoplasm of permeabilized cells, and no annular pattern was conserved. Permeabilization results in the extraction of soluble cytoplasmic components but leaves intact the microtubules and intermediate filaments. In permeabilized cells, CRP deposits were identified as granular deposits with a degree of polarization, probably associated with the formation of intermediate filaments and the anchorage of cells to the plate.

At this point, our data demonstrate that mCRP is present in the cytoplasm of monocyte-derived macrophages, and these findings are in agreement with reports from other studies that identified mCRP antigens intracellularly $(22,42)$. However, the immunofluorescence data are insufficient to enable a clear localization of the mCRP with respect to the cell membrane.

In summary, our findings show that CRP is expressed by monocyte-derived macrophages and that it is produced as the modified rather than the native isomer. In our cell model, mCRP was induced during the differentiation process and was further increased in response to LPS stimulation. 
Since mCRP is reported to have proinflammatory activities, it is of interest to speculate whether natural expression of this protein contributes to the low-grade inflammation that is associated with atherogenesis. In any respect, CRP constitutes an ideal target for pharmacologic interventions directed toward the prevention and treatment of cardiovascular disease. Our ultimate aims were to assess the presence of CRP and to describe its modulation in response to inflammatory stimuli and to characterize the forms of CRP in a cell model relevant for atherosclerosis. The importance of having such a cell model resides in the fact that further mechanistic studies could be easily performed to fully understand the structure and functions of CRP.

We gratefully acknowledge the assistance of Dr. Ye-Sun Lee for her contributions to the laboratory analyses.

1. Ridker PM, Hennekens CH, Buring JE, Rifai N. C-reactive protein and other markers of inflammation in the prediction of cardiovascular disease in women. N Engl J Med 342:836-843, 2000.

2. Ridker PM. High-sensitivity C-reactive protein: potential adjunct for global risk assessment in the primary prevention of cardiovascular disease. Circulation 103:18131818, 2001.

3. Ridker PM, Stampfer MJ, Rifai N. Novel risk factors for systemic atherosclerosis: a comparison of C-reactive protein, fibrinogen, homocysteine, lipoprotein(a), and standard cholesterol screening as predictors of peripheral arterial disease. JAMA 285:2481-2485, 2001.

4. Pearson TA, Mensah GA, Alexander RW, Anderson JL, Cannon RO III, Criqui M, Fadl YY, Fortmann SP, Hong Y, Myers GL, Rifai N, Smith SC Jr, Taubert K, Tracy RP, Vinicor F; Centers for Disease Control and Prevention; American Heart Association. Markers of inflammation and cardiovascular disease: application to clinical and public health practice: a statement for healthcare professionals from the Centers for Disease Control and Prevention and the American Heart Association. Circulation 107: 499-511, 2003.

5. Venugopal SK, Devaraj S, Jialal I. Effect of C-reactive protein on vascular cells: evidence for a proinflammatory, proatherogenic role. Curr Opin Nephrol Hypertens 14:33-37, 2005.

6. Mitaka C. Clinical laboratory differentiation of infectious versus noninfectious systemic inflammatory response syndrome. Clin Chim Acta 351:17-29, 2005.

7. Hurlimann J, Thorbecke GJ, Hochwald GM. The liver as the site of C-reactive protein formation. J Exp Med 123:365-378, 1966.

8. Diehl EE, Haines GK III, Radosevich JA, Potempa LA. Immunohistochemical localization of modified C-reactive protein antigen in normal vascular tissue. Am J Med Sci 319:79-83, 2000.

9. Jabs WJ, Theissing E, Nitschke M, Bechtel JF, Duchrow M, Mohamed S, Jahrbeck B, Sievers HH, Steinhoff J, Bartels C. Local generation of C-reactive protein in diseased coronary artery venous bypass grafts and normal vascular tissue. Circulation 108:14281431, 2003.

10. Yasojima K, Schwab C, McGeer EG, McGeer PL. Human neurons generate C-reactive protein and amyloid P: upregulation in Alzheimer's disease. Brain Res 887:80-89, 2000. 
11. Yasojima K, Schwab C, McGeer EG, McGeer PL. Generation of C- reactive protein and complement components in atherosclerotic plaques. Am J Pathol 158:1039-1051, 2001.

12. Jabs WJ, Logering BA, Gerke P, Kreft B, Wolber EM, Klinger MH, Fricke L, Steinhoff $\mathrm{J}$. The kidney as a second site of human C-reactive protein formation in vivo. Eur $\mathbf{J}$ Immunol 33:152-161, 2003.

13. Schwedler SB, Guderian F, Dammrich J, Potempa LA, Wanner C. Tubular staining of modified C-reactive protein in diabetic chronic kidney disease. Nephrol Dial Transplant 18:2300-2307, 2003.

14. Kobayashi S, Inoue N, Ohashi Y, Terashima M, Matsui K, Mori T, Fujita H, Awano K, Kobayashi K, Azumi H, Ejiri J, Hirata K, Kawashima S, Hayashi Y, Yokozaki H, Itoh H, Yokoyama M. Interaction of oxidative stress and inflammatory response in coronary plaque instability: important role of C-reactive protein. Arterioscler Thromb Vasc Biol 23:1398-1404, 2003.

15. Potempa LA, Maldonado BA, Laurent P, Zemel ES, Gewurz H. Antigenic, electrophoretic and binding alterations of human C-reactive protein modified selectively in the absence of calcium. Mol Immunol 20:1165-1175, 1983.

16. Potempa LA, Siegel JN, Fiedel BA, Potempa RT, Gewurz H. Expression, detection and assay of a neoantigen (Neo-CRP) associated with a free, human C-reactive protein subunit. Mol Immunol 24:531- 541, 1987.

17. Kresl JJ, Potempa LA, Anderson BE. Conversion of native oligomeric to a modified monomeric form of human C-reactive protein. Int J Biochem Cell Biol 30:1415-1426, 1998.

18. Kolb-Bachofen V, Puchta-Teudt N, Egenhofer C. Expression of membrane-associated Creactive protein by human monocytes: indications for a selectin-like activity participating in adhesion. Glycoconj J 12:122-127, 1995.

19. Rees RF, Gewurz H, Siegel JN, Coon J, Potempa LA. Expression of a C-reactive protein neoantigen (neo-CRP) in inflamed rabbit liver and muscle. Clin Immunol Immunopathol 48:95-107, 1988.

20. Radosevich JA, Haines GK, Motie M, Schaul KW, Mehta N, Kolb K, Potempa LA. Immunohistochemical detection of epitopes expressed on CRP and modified-CRP (i.e. neo-CRP) in human normal and diseased tissues. FASEB J 10:A1466,1996.

21. Samberg NL, Bray RA, Gewurz H, Landay AL, Potempa LA. Preferential expression of neo-CRP epitopes on the surface of human peripheral blood lymphocytes. Cell Immunol 116:86-98, 1988.

22. Mantzouranis EC, Goldberger G, Potempa LA, Whitehead AS, Gewurz H, Colten HR. Biosynthesis and postsynthetic assembly of human C- reactive protein (CRP) Ped Res 18:260A, 1984.

23. Torzewski M, Rist C, Mortensen RF, Zwaka TP, Bienek M, Waltenberger J, Koenig W, Schmitz G, Hombach V, Torzewski J. C- reactive protein in the arterial intima: role of Creactive protein receptor-dependent monocyte recruitment in atherogenesis. Arterioscler Thromb Vasc Biol 20:2094-2099, 2000.

24. Pasceri V, Willerson JT, Yeh ET. Direct proinflammatory effect of C-reactive protein on human endothelial cells. Circulation 102:2165-2168, 2000.

25. Zwaka TP, Hombach V, Torzewski J. C-reactive protein-mediated low- density lipoprotein uptake by macrophages: implications for atherosclerosis. Circulation 103:1194-1197, 2001. 
26. Bhakdi S, Torzewski M, Klouche M, Hemmes M. Complement and atherogenesis: binding of CRP to degraded, nonoxidized LDL enhances complement activation. Arterioscler Thromb Vasc Biol 19:2348-2354, 1999.

27. Venugopal SK, Devaraj S, Jialal I. C-reactive protein decreases prostacyclin release from human aortic endothelial cells. Circulation 108:1676-1678, 2003.

28. Potempa LA, Zeller JM, Fiedel BA, Kinoshita CM, Gewurz H. Stimulation of human neutrophils, monocytes, and platelets by modified C-reactive protein (CRP) expressing a neoantigenic specificity. Inflammation 12:391-405, 1988.

29. Zouki C, Haas B, Chan JS, Potempa LA, Filep JG. Loss of pentameric symmetry of Creactive protein is associated with promotion of neutrophil-endothelial cell adhesion. $\mathbf{J}$ Immunol 167:5355-5361, 2001.

30. Khreiss T, Jozsef L, Potempa LA, Filep JG. Conformational rearrangement in C-reactive protein is required for proinflammatory actions on human endothelial cells. Circulation 109:2016-2022, 2004.

31. Khreiss T, Jozsef L, Potempa LA, Filep JG. Opposing effects of C- reactive protein isoforms on shear-induced neutrophil-platelet adhesion and neutrophil aggregation in whole blood. Circulation 110:2713-2720, 2004.

32. Ying SC, Gewurz H, Kinoshita CM, Potempa LA, Siegel JN. Identification and partial characterization of multiple native and neoantigenic epitopes of human C-reactive protein by using monoclonal antibodies. J Immunol 143:221-228, 1989.

33. Ying SC, Shephard E, deBeer FC, Siegel JN, Harris D, Gewurz BE, Fridkin M, Gewurz $\mathrm{H}$. Localization of sequence-determined neoepitopes and neutrophil digestion fragments of C-reactive protein utilizing monoclonal antibodies and synthetic peptides. Mol Immunol 29:677-687, 1992.

34. Meduri GU, Kanangat S, Stefan J, Tolley E, Schaberg D. Cytokines IL1beta, IL-6, and TNF-alpha enhance in vitro growth of bacteria. Am J Respir Crit Care Med 160:961-967, 1999.

35. Khattri R, Hansen B, Nichols TC, Palmer KL, Gilman-Sachs A, Baum LL. Anti-Creactive protein inhibits cytoskeletal rearrangement without altering calcium influx in natural killer cell activation. Cell Immunol 155:457-475, 1994.

36. Lehto VP, Hovi T, Vartio T, Badley RA, Virtanen I. Reorganization of cytoskeletal and contractile elements during transition of human monocytes into adherent macrophages. Lab Invest 47:391-399, 1982.

37. Juliano RL, Haskill S. Signal transduction from the extracellular matrix. J Cell Biol 120:577-585, 1993.

38. Ganapathi MK, Rzewnicki D, Samols D, Jiang SL, Kushner I. Effect of combinations of cytokines and hormones on synthesis of serum amyloid A and C-reactive protein in Hep 3B cells. J Immunol 147:1261-1265, 1991.

39. Moshage HJ, Roelofs HM, van Pelt JF, Hazenberg BP, van Leeuwen MA, Limburg PC, Aarden LA, Yap SH. The effect of interleukin-1, interleukin-6 and its interrelationship on the synthesis of serum amyloid A and C-reactive protein in primary cultures of adult human hepatocytes. Biochem Biophys Res Commun 155:112-117, 1988.

40. Calabro P, Willerson JT, Yeh ET. Inflammatory cytokines stimulated C-reactive protein production by human coronary artery smooth muscle cells. Circulation 108:1930-1932, 2003. 
41. Ramage L, Guy K. Expression of C-reactive protein and heat-shock protein-70 in the lung epithelial cell line A549, in response to PM10 exposure. Inhal Toxicol 16:447-452, 2004.

42. Vaith P, Prasauskas V, Potempa LA, Peter HH. Complement activation by C-reactive protein on the HEp-2 cell substrate. Int Arch Allergy Immunol 111:107-117, 1996. 